\title{
39. DISTRIBUTION OF IRIDIUM AND OTHER ELEMENTS NEAR THE CRETACEOUS/ TERTIARY BOUNDARY IN HOLE 465A: PRELIMINARY RESULTS ${ }^{1}$
}

\author{
H. V. Michel and F. Asaro, Lawrence Berkeley Laboratory, Berkeley, California \\ W. Alvarez, Department of Geology and Geophysics, University of California at Berkeley \\ and \\ L. W. Alvarez, Space Sciences Laboratory, University of California at Berkeley
}

\section{INTRODUCTION}

Very significant enhancements of the element iridium have been observed in association with the Cretaceous/Tertiary boundary in marine sediments laid down $65 \mathrm{~m} . \mathrm{y}$. ago and subsequently uplifted above the ocean's surface. If our hypothesis for the origin of the iridium and the cause of the Cretaceous/Tertiary life extinctions (the asteroid-impact theory) (Alvarez et al., 1980) is correct, the Ir anomaly should be associated with the Cretaceous/Tertiary boundary region wherever it is intact. The present work was undertaken to search for the Ir anomaly in a deep-sea-drilling core, in order to check this aspect of the asteroid-impact theory.

\section{CORE DESCRIPTIONS}

Basal Tertiary (Paleocene) sediments have been identified $144 \mathrm{~cm}$ below the top of Section 3 of Core 3 from Deep Sea Drilling Project Hole 465A, and Cretaceous sediments were identified $2 \mathrm{~cm}$ lower (Site 465 report, this volume). The Cretaceous just below the $144-\mathrm{cm}$ level has been described as very white. The region above is a darker white and has dark blobs described as mainly pyrite. Fifty centimeters below the top of Section 3, the color is very white again. There are streaks of the very white material which intrude into the region above the $144-\mathrm{cm}$ level. The edges of these streaks are sometimes flecked with the dark material.

\section{SAMPLING}

Nine samples which bracket the expected Cretaceous/Tertiary boundary region were obtained. Seven of these contained only light-colored components, but two also contained the dark blobs. In the latter two samples, the light and dark fractions were manually separated with forceps. Both fractions were studied. The positions in the core of the 11 samples used in this study are identified in Table 1.

\section{MEASUREMENTS}

All samples were measured by high-precision methods of neutron-activation analysis (Perlman and Asaro, 1969). Most elements were calibrated against the "Standard Pottery" multi-element standard (Perlman and

\footnotetext{
'Initial Reports of the Deep Sea Drilling Project, Volume 62.
}

Table 1. Concordance of sample names.

\begin{tabular}{crc}
\hline DSDP Designation & NAA Sample Name & NAA Pill Name \\
\hline $465 \mathrm{~A}-3-3,80-82 \mathrm{~cm}$ & DSEA-14 & $2005-\mathrm{M}$ \\
$98-100 \mathrm{~cm}$ & -15 & $-\mathrm{N}$ \\
$112-114 \mathrm{~cm}$ & -16 & $-\mathrm{O}$ \\
$118-120 \mathrm{~cm}$ & -21 & $-\mathrm{T}$ \\
$141-143 \mathrm{~cm}$ & -19 & $-\mathrm{R}$ \\
$144-146 \mathrm{~cm}$ & -17 & $-\mathrm{P}$ \\
$3-4,2 \mathrm{~cm}$ & -11 & $-\mathrm{H}$ \\
$10-12 \mathrm{~cm}$ & -12 & $-\mathrm{J}$ \\
$20-22 \mathrm{~cm}$ & -13 & $-\mathrm{K}$ \\
Separated pyrite-containing fractions & \\
$3-3,118-120$ & -20 & $-\mathrm{S}$ \\
$141-143$ & -18 & $-\mathrm{Q}$ \\
\hline
\end{tabular}

Asaro, 1971). Chlorine and calcium were calibrated against primary standards, and $\mathrm{Ir}$ was standardized against a carefully calibrated sample of the Danish Cretaceous/Tertiary boundary layer at Stevns Klint. The data are shown in Tables 2 through 5 . The listed errors are 1-sigma values of the statistical uncertainties in counting gamma rays. The precision of measurements is about equal to these errors. Corrections have been made for all known gamma-ray interferences. The accuracies should be close to the precisions for those elements measured against primary standards or "Standard Pottery"; in the latter instance, the accuracies may be determined more closely by coupling the precisions with the uncertainties in the element abundances in "Standard Pottery" (Perlman and Asaro, 1971). Several elements $(\mathrm{Ag}, \mathrm{Br}, \mathrm{Cu}, \mathrm{Mg}, \mathrm{Se}$, and $\mathrm{Zn}$ ) were calibrated against flux monitors and contain about $10 \%$ additional uncertainty.

\section{CONCLUSIONS}

A large enrichment of Ir was found in the region of the Cretaceous/Tertiary boundary, as predicted by the asteroid-impact theory. The Ir enrichment is distributed over $\sim 40 \mathrm{~cm}$ of core and is associated both with black blobs and (predominantly) with the light-colored fraction.

The light-colored fraction between 100 and $144 \mathrm{~cm}$ below the top of Section 3 is principally $\mathrm{CaCO}_{3}$, but probably contains significant amounts of clay, which may contribute to its gray color. The total estimated clay in this region is roughly $9 \mathrm{~g} / \mathrm{cm}^{2}$, about seven times 
Table 2. Major-element, bromine, and strontium abundances.

\begin{tabular}{|c|c|c|c|c|c|c|c|c|c|}
\hline Sample & $\begin{array}{c}\text { Ca Expressed } \\
\text { as } \mathrm{CaCO}_{3}{ }^{\mathrm{a}} \\
(\%)\end{array}$ & $\begin{array}{l}\text { Al Expressed } \\
\text { as } \mathrm{Al}_{2} \mathrm{O}_{3} \\
(\%)\end{array}$ & $\begin{array}{c}\mathrm{Cl} \\
(\%)\end{array}$ & $\begin{array}{c}\mathrm{Na}(\%) \\
\text { after } 0.556 \\
\text { of } \mathrm{Cl} \\
\text { Abundance } \\
\text { Removedb } \\
(\%)\end{array}$ & $\begin{array}{l}\mathrm{Mg}^{\mathrm{c}} \\
(\%)\end{array}$ & $\begin{array}{l}\mathrm{Fe} \\
(\%)\end{array}$ & $\begin{array}{c}\mathrm{Br} \\
(\mathrm{ppm})\end{array}$ & $\begin{array}{c}\text { Residual } \\
\text { Br after } \\
0.0034 \text { of } \\
\text { Cl Abundance } \\
\text { Removedd } \\
\text { (ppm) }\end{array}$ & $\begin{array}{c}\mathrm{Sr} \\
(\mathrm{ppm})\end{array}$ \\
\hline 2005-M & $92.4 \pm 2.2$ & $0.22 \pm 0.05$ & $0.850 \pm 0.030$ & $0.054 \pm 0.018$ & $<0.6$ & $0.068 \pm 0.001$ & $32.8 \pm 1.3$ & $<7$ & $1271 \pm 127$ \\
\hline$-\mathrm{N}$ & $92.4 \pm 2.2$ & $0.65 \pm 0.08$ & $1.274 \pm 0.035$ & $0.111 \pm 0.020$ & $<1.4$ & $0.3164 \pm 0.0032$ & $52.3 \pm 1.6$ & $8.7 \pm 2.0$ & $1023 \pm 111$ \\
\hline-0 & $85.4 \pm 2.5$ & $1.67 \pm 0.13$ & $1.488 \pm 0.038$ & $0.244 \pm 0.022$ & $<1.2$ & $0.542 \pm 0.005$ & $56.7 \pm 1.7$ & $<10$ & $852 \pm 100$ \\
\hline$-\mathrm{T}$ & $89.4 \pm 2.2$ & $1.34 \pm 0.11$ & $1.020 \pm 0.032$ & $0.202 \pm 0.019$ & $<0.9$ & $0.3404 \pm 0.0035$ & $37.0 \pm 1.4$ & $<6$ & $858 \pm 100$ \\
\hline$-R$ & $86.9 \pm 2.0$ & $2.28 \pm 0.07$ & $0.878 \pm 0.031$ & $0.225 \pm 0.018$ & $<1.25$ & $0.453 \pm 0.005$ & $31.9 \pm 1.4$ & $<5$ & $921 \pm 104$ \\
\hline$-P$ & $96.9 \pm 2.5$ & $0.25 \pm 0.13$ & $1.001 \pm 0.032$ & $0.049 \pm 0.019$ & $<1.4$ & $0.044 \pm 0.001$ & $37.7 \pm 1.3$ & $<7$ & $939 \pm 100$ \\
\hline$-\mathrm{H}$ & $94 \pm 4$ & $<4$ & $2.12 \pm 0.05$ & $<0.06$ & $<2.3$ & $0.025 \pm 0.001$ & $71.9 \pm 1.6$ & $<5$ & $1029 \pm 110$ \\
\hline$-\mathbf{J}$ & $98 \pm 4$ & $<6$ & $2.14 \pm 0.07$ & $<0.11$ & $<1.9$ & $0.026 \pm 0.001$ & $75.0 \pm 1.7$ & $<8$ & $982 \pm 108$ \\
\hline$-\mathrm{K}$ & $99.9 \pm 1.8$ & $0.323 \pm 0.031$ & $0.699 \pm 0.028$ & $0.039 \pm 0.017$ & $<1.1$ & $0.048 \pm 0.001$ & $22.9 \pm 1.1$ & $<3$ & $965 \pm 99$ \\
\hline \multicolumn{10}{|c|}{ Separated pyrite-containing fraction } \\
\hline$-S$ & $4.5 \pm 1.6$ & $9.01 \pm 0.22$ & $3.17 \pm 0.05$ & $0.84 \pm 0.03$ & $2.9 \pm 0.8$ & $11.2 \pm 0.1$ & $105.2 \pm 3.6$ & $<8$ & $<650$ \\
\hline$-Q$ & $13.2 \pm 1.4$ & $8.47 \pm 0.13$ & $2.66 \pm 0.12$ & $0.87 \pm 0.07$ & $3.2 \pm 0.7$ & $9.56 \pm 0.11$ & $89.9 \pm 3.5$ & $<11$ & $<640$ \\
\hline
\end{tabular}

a Sea water contributions of $0.2 \%$ and $0.1 \%$ were subtracted from the $\mathrm{CaCO}_{3}$ abundances in samples 2005-S and 2005-Q, respectively.

b In sea water the $\mathrm{Na} / \mathrm{Cl}$ ratio is given as 0.556 .

c Sea water contributions of $0.2 \%$ were subtracted from the $\mathrm{Mg}$ abundances in samples 2005-S and 2005-Q.

$\mathrm{d}_{\mathrm{In}}$ sea water the $\mathrm{Br} / \mathrm{Cl}$ ratio is given as 0.0034 .

Table 3. Rare-earth, barium, and scandium abundances (ppm).

\begin{tabular}{|c|c|c|c|c|c|c|c|c|c|c|c|}
\hline Sample & $\mathrm{La}$ & $\mathrm{Ce}$ & Nd & Sm & Eu & $\mathrm{Tb}$ & Dy & $\mathrm{Yb}$ & Lu & $\mathrm{Ba}$ & Sc \\
\hline 05-M & $21.57 \pm 0.38$ & $2.98 \pm 0.10$ & $16.9 \pm 0.6$ & $3.256 \pm 0.033$ & $0.856 \pm 0.011$ & $0.628 \pm 0.015$ & $4.55 \pm 0.07$ & $2.734 \pm 0.027$ & $0.353 \pm 0.007$ & $1167 \pm 15$ & $2.054 \pm 0.021$ \\
\hline$-\mathrm{N}$ & $26.2 \pm$ & $4.75 \pm 0.11$ & $21.6 \pm 0.7$ & $4.09 \pm 0.04$ & $1.081 \pm 0.013$ & $0.768 \pm 0.018$ & $5.28 \pm 0.08$ & $3.164 \pm 0.032$ & $0.397 \pm 0.009$ & & \\
\hline-0 & $27.5 \pm 0.5$ & $6.48 \pm 0.14$ & $23.2 \pm 0.7$ & $4.60 \pm 0.05$ & $1.209 \pm 0.013$ & $0.847 \pm 0.020$ & $5.83 \pm 0.09$ & $2.962 \pm 0.030$ & $0.371 \pm 0.009$ & $1335 \pm 19$ & $4.78 \pm 0.05$ \\
\hline$-\mathrm{T}$ & $24.3 \pm 0.4$ & $5.64 \pm 0.13$ & $21.3 \pm 0.7$ & $3.98 \pm 0.04$ & $1.056 \pm 0.013$ & $0.748 \pm 0.018$ & $5.10 \pm 0.08$ & $2.832 \pm$ & $0.372 \pm 0.009$ & $1196 \pm 18$ & $3.567 \pm 0.036$ \\
\hline$-R$ & $13.58 \pm$ & 3 & 10.8 & 2.171 & & & & & & & $4.81 \pm 0.05$ \\
\hline$-\stackrel{P}{P}$ & $13.84 \pm 0.33$ & $2.25 \pm 0.09$ & $11.2 \pm 0.5$ & $2.176 \pm 0.022$ & $0.564 \pm 0.009$ & $0.410 \pm 0.012$ & $2.99 \pm 0.06$ & $1.818 \pm 0.020$ & 0.231 & $659 \pm 12$ & $1.215 \pm 0.012$ \\
\hline$-\mathrm{H}$ & $13.10 \pm$ & $1.91=$ & 10.5 & 1.92 & & & & 1.7 & & & $0.970 \pm 0.010$ \\
\hline$-\mathrm{J}$ & $14.15 \pm$ & $2.09 \pm$ & $11.1 \pm$ & $2.132 \pm$ & $0.558 \pm$ & 0.394 & $2.72=$ & $1.787 \pm$ & 0.22 & & $1.046 \pm 0.010$ \\
\hline$-\mathrm{K}$ & $13.66 \pm 0.30$ & $2.01 \pm 0.09$ & 11.1 & $2.09 \pm 0$ & 0.542 . & 0.418 & $2.86=$ & $1.763 \pm 0$ & $0.225 \pm 0.006$ & $594 \pm 10$ & $1.162 \pm 0.012$ \\
\hline \multicolumn{12}{|c|}{ Separated pyrite-containing fraction } \\
\hline$-S$ & $4.07 \pm 0.7$ & & - & & & & & - & 0.03 & & - \\
\hline$-Q$ & & $29 \pm 0.21$ & - & $1.065 \pm 0.011$ & $0.34 \pm 0.09$ & $0.180 \pm 0.027$ & $1.41 \pm 0.16$ & - & $0.070 \pm 0.015$ & $245 \pm 24$ & - \\
\hline
\end{tabular}

Table 4. Abundances (ppm) of elements enhanced by over a factor of 100 in the pyrite-containing fractions, relative to the Cretaceous calcareous samples.

\begin{tabular}{|c|c|c|c|c|c|c|c|c|c|}
\hline Sample & As & $\mathrm{Cr}$ & Co & $\mathrm{Cu}^{\mathrm{a}}$ & Mo & $\mathrm{Ni}$ & $\mathrm{Sb}$ & $\mathrm{Ta}$ & $\mathrm{Zn}^{\mathrm{a}}$ \\
\hline$-\mathrm{N}$ & $<3.5$ & $9.5 \pm 0.4$ & $4.51 \pm 0.12$ & $<64$ & $<1.6$ & $19.14 \pm 0.55$ & $0.23 \pm 0.04$ & $0.0200 \pm 0.0026$ & $18.5 \pm 2.2$ \\
\hline$-R$ & $5.4 \pm 0.9$ & $68.8 \pm 0.8$ & $8.44 \pm 0.17$ & $<87$ & $3.3 \pm 0.4$ & $64.9 \pm 1.3$ & $0.78 \pm 0.08$ & $0.0779 \pm 0.0028$ & $45.7 \pm 2.9$ \\
\hline$-P$ & $2.3 \pm 0.8$ & $2.97 \pm 0.25$ & $0.56 \pm 0.04$ & $<47$ & $<1.0$ & $4.09 \pm 0.17$ & $<0.07$ & $0.0054 \pm 0.0020$ & $14.6 \pm 1.5$ \\
\hline$-\mathrm{H}$ & $<2.7$ & $1.00 \pm 0.23$ & $0.38 \pm 0.04$ & - & $<0.5$ & $4.19 \pm 0.14$ & $0.28 \pm 0.04$ & $0.0065 \pm 0.0022$ & $10.4 \pm 1.4$ \\
\hline \multicolumn{10}{|c|}{ Separated pyrite-containing fraction } \\
\hline$-S$ & $111 \pm 4$ & $393 \pm 6$ & $402 \pm 4$ & $954 \pm 56$ & $40.7 \pm 2.7$ & $1722 \pm 39$ & $16.3 \pm 0.8$ & $0.592 \pm 0.006$ & $-10^{3}$ \\
\hline$-\mathrm{Q}$ & $99 \pm 4$ & $388 \pm 4$ & $310.7 \pm 3.3$ & $756 \pm 51$ & $98 \pm 6$ & $1322 \pm 32$ & $18.1 \pm 0.9$ & $0.594 \pm 0.008$ & $-8 \times 10^{2}$ \\
\hline
\end{tabular}

a Flux monitors were used in calibration; there is a systematic uncertainty of $10-20 \%$ for each element. 
Table 5. Abundances (ppm) of other elements enhanced by over a factor of 10 in the pyrite-containing fractions relative to the Cretaceous calcareous samples.

\begin{tabular}{rrrrrrrr}
\hline Sample & \multicolumn{1}{c}{$\mathrm{Ag}^{\mathrm{a}}$} & $\mathrm{Ir}(\mathrm{ppb})$ & \multicolumn{1}{c}{$\mathrm{Mn}$} & \multicolumn{1}{c}{$\mathrm{Se}^{\mathrm{a}}$} & \multicolumn{1}{c}{$\mathrm{Th}$} & $\mathrm{U}$ & $\mathrm{V}$ \\
\hline $2005-\mathrm{M}$ & $<0.8$ & $0.78 \pm 0.09$ & $147.7 \pm 3.0$ & $<0.5$ & $0.096 \pm 0.013$ & $0.117 \pm 0.015$ & $<25$ \\
$-\mathrm{N}$ & $<0.8$ & $3.70 \pm 0.27$ & $224 \pm 4$ & $<0.5$ & $0.341 \pm 0.029$ & $0.197 \pm 0.018$ & $<20$ \\
$-\mathrm{O}$ & $<1.3$ & $9.86 \pm 0.48$ & $210 \pm 4$ & $<0.6$ & $1.053 \pm 0.035$ & $0.286 \pm 0.020$ & $<51$ \\
$-\mathrm{T}$ & $<1.3$ & $5.77 \pm 0.36$ & $190.1 \pm 3.8$ & $<0.4$ & $0.618 \pm 0.032$ & $0.192 \pm 0.018$ & $<23$ \\
$-\mathrm{R}$ & $<1.2$ & $3.03 \pm 0.14$ & $243 \pm 5$ & $<0.4$ & $1.801 \pm 0.030$ & $0.165 \pm 0.016$ & $<32$ \\
$-\mathrm{P}$ & $<0.6$ & $0.70 \pm 0.07$ & $123.7 \pm 2.5$ & $<0.5$ & $0.090 \pm 0.010$ & $0.101 \pm 0.014$ & $40 \pm 13$ \\
$-\mathrm{H}$ & $<0.6$ & $0.26 \pm 0.05$ & $118.1 \pm 2.4$ & $<0.4$ & $0.066 \pm 0.009$ & $0.078 \pm 0.017$ & - \\
$-\mathrm{J}$ & $<0.5$ & $0.39 \pm 0.08$ & $126.8 \pm 2.5$ & $<0.3$ & $0.067 \pm 0.010$ & $0.084 \pm 0.017$ & - \\
$-\mathrm{K}$ & $<0.8$ & $0.55 \pm 0.08$ & $121.8 \pm 2.4$ & $<0.5$ & $0.098 \pm 0.010$ & $0.100 \pm 0.013$ & $<20$ \\
Separated pyrite-containing fraction & & & & & \\
$-\mathrm{S}$ & $5.0 \pm 1.0$ & $10.2 \pm 0.8$ & $2146 \pm 43$ & $6.58 \pm 0.17$ & $2.286 \pm 0.023$ & $0.726 \pm 0.040$ & $112 \pm 23$ \\
$-\mathrm{Q}$ & $3.5 \pm 1.0$ & $14.5 \pm 0.9$ & $1406 \pm 28$ & $4.5 \pm 0.5$ & $3.13 \pm 0.07$ & $0.829 \pm 0.039$ & $129 \pm 17$ \\
\hline
\end{tabular}

a Flux monitors were used in the calibration; there is a systematic uncertainty of $10-20 \%$ for each element.

as much as in the Danish (Stevns Klint) or Italian (Gubbio) Cretaceous/Tertiary boundary layers. Although many elements have roughly the same ratios in the lightcolored fraction, they do differ somewhat, especially in Ir. The total Ir enrichment is about $520 \mathrm{ng} / \mathrm{cm}^{2}$-about 6.5 times the Danish value, and about 35 times the Italian value.

There are very significant $\mathrm{Ce}$ depletions in the Cretaceous samples and the Tertiary sample from $\sim 80 \mathrm{~cm}$ below the top of Section 3. In the region between 100 and $144 \mathrm{~cm}$ below the top of Section 3, the Ce depletion is not as great. This suggests a rare-earth component from a source other than sea water.

The two studied dark blobs probably are principally aluminum magnesium silicate (clay). They have abundant iron, and (from other work) they probably contain pyrite; the maximum abundance of pyrite in these blobs is about $25 \%$. The two blobs are very enriched in a number of elements which form insoluble sulfides, but they are not identical in composition: the abundance of Mo, for example, differs by a factor of two in the two samples. Rare-earth abundances are very low in the dark blobs; this may in part be because of incompletely separated light-colored material (which contains higher abundances of rare earths). There is excess $\mathrm{Ce}$ in these rare-earth patterns over the amount expected from the $\mathrm{Sm}$ abundance and the $\mathrm{Ce} / \mathrm{Sm}$ ratio in the Cretaceous calcareous fraction.

\section{ACKNOWLEDGMENTS}

We are very appreciative to Roger $\mathrm{R}$. Revelle for suggesting the study. Charles G. Adelseck, Jr., most kindly assisted in selecting the samples. We are grateful to Tek Lim, supervisor of the Berkeley Research reactor, and his staff for the irradiations used in the measurements.

Funding for this work was provided by the California Space Group and the National Aeronautics and Space Administration Ames Research Center.

\section{REFERENCES}

Alvarez, L. W., Alvarez, W., Asaro, F., et al., 1980. Extraterrestrial cause for the Cretaceous-Tertiary extinction. Science, 208:10951108.

Perlman, I., and Asaro, F., 1969. Pottery analysis by neutron activation. Archaeometry, 11:21-52. 1971. In Brill, R. H. (Ed.), Science and Archaeology: Cambridge (MIT Press), p. 182. 